\title{
Interrelationship between partition behavior of organic compounds and proteins in aqueous dextran-polyethylene glycol and polyethylene glycol-sodium sulfate two-phase systems
}

\author{
Luisa A. Ferreira ${ }^{a}$, Nuno R. da Silva ${ }^{b}$, Samarina R. Wlodarczyk ${ }^{c}$, Joana A. Loureiro ${ }^{d}$, \\ Pedro P. Madeira e,f , José A. Teixeira ${ }^{\mathrm{b}}$, Vladimir N. Uversky ${ }^{\mathrm{g}}$, Boris Y. Zaslavsky ${ }^{\mathrm{a}, *}$ \\ a Analiza, Inc., 3615 Superior Ave., Cleveland, OH 44114, USA \\ b IBB-Institute for Biotechnology and Bioengineering, Centre of Biological Engineering, Universidade do Minho, Campus de Gualtar, 4710-057 Braga, \\ Portugal \\ c Universidade de São Paulo, Faculdade de Ciencias Farmaceuticas, Laboratório de Biologia Molecular Aplicada à Biotecnologia Farmacêutica, São Paulo, \\ Brazil \\ ${ }^{\mathrm{d}}$ LEPABE, Department of Chemical Engineering, Faculty of Engineering of the University of Porto, 4200-465 Porto, Portugal \\ e Centro de Investigacao em Materiais Ceramicos e Compositos, Department of Chemistry, Aveiro, Portugal, Portugal \\ ${ }^{\mathrm{f}}$ Laboratory of Separation and Reaction Engineering-Laboratory of Catalysis and Materials (LSRE-LCM), Porto, Portugal \\ ${ }^{g}$ Department of Molecular Medicine, Morsani College of Medicine, University of South Florida, Tampa, FL 33612, USA
}

\section{A R T I C L E I N F O}

\section{Article history:}

Received 5 February 2016

Received in revised form 14 March 2016

Accepted 14 March 2016

Available online 17 March 2016

\section{Keywords:}

Aqueous two-phase partitioning

Aqueous two phase systems

Dex-PEG system

PEG-sodium sulfate system

Mononucleotides

Phosphate group

\begin{abstract}
A B S T R A C T
Partition behavior of adenosine and guanine mononucleotides was examined in aqueous dextranpolyethylene glycol (PEG) and PEG-sodium sulfate two-phase systems. The partition coefficients for each series of mononucleotides were analyzed as a functions of the number of phosphate groups and found to be dependent on the nature of nucleic base and on the type of ATPS utilized. It was concluded that an average contribution of a phosphate group into logarithm of partition coefficient of a mononucleotide cannot be used to estimate the difference between the electrostatic properties of the coexisting phases of ATPS.

The data obtained in this study were considered together with those for other organic compounds and proteins reported previously, and the linear interrelationship between logarithms of partition coefficients in dextran-PEG, PEG-Na $\mathrm{SO}_{4}$ and PEG-Na $\mathrm{SO}_{4}-0.215 \mathrm{M} \mathrm{NaCl}$ (all in $0.01 \mathrm{M}$ Na- or K/Na-phosphate buffer, $\mathrm{pH} 7.4$ or 6.8) was established. Similar relationship was found for the previously reported data for proteins in Dex-PEG, PEG-600- $\mathrm{Na}_{2} \mathrm{SO}_{4}$, and PEG-8000- $\mathrm{Na}_{2} \mathrm{SO}_{4}$ ATPS. It is suggested that the linear relationships of the kind established in ATPS may be observed for biological properties of compounds as well.
\end{abstract}

(c) 2016 Elsevier B.V. All rights reserved.

\section{Introduction}

There are two main types of aqueous two-phase systems (ATPS) [1-5]. The first type includes those formed in aqueous mixtures of two different polymers, such as dextran and Ficoll or polyethylene glycol (PEG). These ATPS are used for separation of cells and other biological particles [1-4]. The second type of ATPS includes systems formed in aqueous mixtures of a single polymer, such as PEG or polypropylene glycol, and a salt, such as sodium sulfate, phosphate, citrate, and these ATPS are generally used for protein separation [6]. Both these types of ATPS may be used for analytical applications [7]. The third type of ATPS being recently developed

\footnotetext{
* Corresponding author.

E-mail address: bz@analiza.com (B.Y. Zaslavsky).
}

and characterized [8] is the ATPS formed in water by mixing ionic liquids and inorganic salts or polymers. This family of ATPS is used successfully for separation purposes but presents a particular challenge in regard to the mechanism of solute partitioning. It has been established [7] that solute partition behavior in polymer-polymer ATPS and to a lesser degree in polymer-salt ATPS is governed by the solute-water interactions whithout direct interactions of the solute with the phase-forming components of ATPS. The question of direct solute-ionic liquid interactions in the ionic liquid-salt ATPS, however, remains open.

It has been reported by us recently that various properties of polar organic compounds and proteins in aqueous solutions (solubility [9], lipophilicity (expressed as $\log D$ values in octanol-water system) [10], partition coefficients in aqueous two-phase systems (ATPS) [11]) in the presence of different salt additives, and optical rotation of enantiomeric amino acids and glucose in aqueous 
solutions in the presence of different salts $[12,13]$ are interrelated as:

$\log \mathrm{SP}_{\text {salt }-1}=\mathrm{k}_{1}+\mathrm{k}_{2} \times \log \mathrm{SP}_{\text {salt }-2}+\mathrm{k}_{3} \times \operatorname{logS\mathrm {P}_{\text {salt}-3}}$

where $\mathrm{SP}_{\text {salt }}$ is the property of a solute in the presence of a given salt additive, $\mathrm{k}_{1}, \mathrm{k}_{2}$, and $\mathrm{k}_{3}$ are constants depending on the solute property under consideration and the salt compositions employed.

From a practical point of view, the most important aspect of the relationship described by Eq. (1) is that once the relationship is established it may be used to predict protein partition coefficient in a system with a certain ionic composition without need to perform experiments saving the necessary protein quantity to be used, time and labor. It may be important when the optimal separation conditions for a target protein are designed. From the theoretical viewpoint the relationship described by Eq. (1) if applicable to both polymer-polymer and polymer-salt ATPS may be used to gain better understanding in what respect these two different subfamilies of ATPS are similar or different and derive better insight into mechanisms of phase separation and fundamental properties of ATPS.

Analysis of the partition coefficients of small organic compounds and proteins in dextran-PEG and PEG-sodium sulfate ATPS was one of the aims of this study. In addition, the second aim of the study was to explore if the homologous series of mononucleotides may be used for characterization of ATPS. Partitioning of adenine and adenosine mono-, di-, and tri-phosphates and guanosine mono-, di-, and tri-phosphates in dextran-PEG and PEG-Na ${ }_{2} \mathrm{SO}_{4}$ with and without $0.215 \mathrm{M} \mathrm{NaCl}$ additive ATPS were examined to explore if contribution of a phosphate group into logarithm of partition coefficient of mononucleotide may be used for characterization of electrostatic properties of coexisting phases in ATPS.

\section{Experimental}

\subsection{Material and methods}

\subsubsection{Materials}

Polyethylene glycol 8000 (Lot 091M01372 V), Mw =8000, adenine, adenosine, adenosine $5^{\prime}$-monophosphate disodium salt (AMP), adenosine 5'-diphosphate sodium salt (ADP), adenosine triphosphate sodium salt (ATP), guanosine, guanosine 5'-monophosphate disodium salt (GMP), guanosine 5'-diphosphate sodium salt (GDP), guanosine $5^{\prime}$-triphosphate sodium salt (GTP) were purchased from Sigma-Aldrich (St. Louis, MO, USA). Dextran75 (Lot 119945 ) with an average molecular weight $\left(M_{w}\right) 75,000$ by light scattering were purchased from USB Corporation (Cleveland, $\mathrm{OH}, \mathrm{USA}$ ).

\subsubsection{Two-phase systems}

Dextran-PEG systems of polymer composition of $6.0 \mathrm{wt}$.\% PEG8000 and 12.0 wt.\% Dex-75 and ionic composition of $0.01 \mathrm{M} \mathrm{K} / \mathrm{NaPB}$, $\mathrm{pH} 7.4$ and PEG-8000- $\mathrm{Na}_{2} \mathrm{SO}_{4}$ systems with composition of 11.10 wt\% PEG-8000, $6.33 \mathrm{wt} \% \mathrm{Na}_{2} \mathrm{SO}_{4}(\sim 0.45 \mathrm{M})$ and $0.01 \mathrm{M} \mathrm{NaPB}$, $\mathrm{pH} 6.8$, with or without $0.215 \mathrm{M} \mathrm{NaCl}$ additive were prepared as described previously $[11,14,15]$ by dispensing appropriate amounts of the aqueous stock polymer and salt solutions into a $1.2 \mathrm{~mL}$ microtube using a Hamilton Company (Reno, NV, USA) ML4000 four-probe liquid-handling workstation. with total weight of $0.5 \mathrm{~g}$ (total volume $470 \mu 1$ ).

\subsubsection{Partitioning}

All partition experiments were performed with the Automated Signature Workstation, ASW (Analiza, Inc., Cleveland, OH, USA) as described elsewhere $[11,14,15]$. The ASW system is based on the ML-4000 liquid-handling workstation (Hamilton Company, Reno,
Table 1

Differences between the solvent properties of the phases and partition coefficients for indicated organic compounds in Dex-PEG-0.01 M K/NaPB, pH 7.4, PEG- $\mathrm{Na}_{2} \mathrm{SO}_{4}$ $0.01 \mathrm{M} N a P B, p H$ 6.8, and PEG- $\mathrm{Na}_{2} \mathrm{SO}_{4}-0.215 \mathrm{M} \mathrm{NaCl}-0.01 \mathrm{M} \mathrm{NaPB}, \mathrm{pH} 6.8$ ATPS (NaPB-sodium phosphate buffer; K/NaPB-sodium/potassium phosphate buffer).

\begin{tabular}{llll}
\hline Solvent properties & $\begin{array}{l}\mathrm{Dex}-\mathrm{PEG} \\
0.01 \mathrm{M} \mathrm{NaPB}\end{array}$ & $\begin{array}{l}\mathrm{PEG}-\mathrm{Na}_{2} \mathrm{SO}_{4} \\
0.01 \mathrm{M} \mathrm{K} / \mathrm{NaPB}^{\mathrm{b}}\end{array}$ & $\begin{array}{l}\mathrm{PEG}^{\mathrm{N}} \mathrm{Na}_{2} \mathrm{SO}_{4} \\
0.215 \mathrm{M} \mathrm{NaCl}^{\mathrm{b}}\end{array}$ \\
\hline$\Delta \mathrm{G}\left(\mathrm{CH}_{2}\right)(\mathrm{cal} / \mathrm{mole})$ & $-45 \pm 1.2$ & $-122 \pm 1.8$ & $-135 \pm 0.6$ \\
$\mathrm{E}$ & $0.033 \pm 0.001$ & $0.090 \pm 0.002$ & $0.102 \pm 0.008$ \\
$\mathrm{C}$ & $0.058 \pm 0.003$ & $0.445 \pm 0.005$ & $0.49 \pm 0.031$ \\
Compound & & & \\
Adenine & $1.220 \pm 0.006^{\mathrm{a}}$ & $3.4 \pm 0.12^{\mathrm{b}}$ & $3.7 \pm 0.16^{\mathrm{b}}$ \\
Adenosine & $1.128 \pm 0.004^{\mathrm{a}}$ & $2.63 \pm 0.02^{\mathrm{c}}$ & $3.12 \pm 0.04^{\mathrm{c}}$ \\
AMP & $0.714 \pm 0.001$ & $1.02 \pm 0.05^{\mathrm{b}}$ & $0.83 \pm 0.04^{\mathrm{b}}$ \\
ADP & $0.769 \pm 0.002$ & $0.77 \pm 0.02^{\mathrm{b}}$ & $0.54 \pm 0.03^{\mathrm{b}}$ \\
ATP & $0.826 \pm 0.002$ & $0.61 \pm 0.01^{\mathrm{b}}$ & $0.40 \pm 0.02^{\mathrm{b}}$ \\
Guanosine & $1.068 \pm 0.007$ & $1.673 \pm 0.008^{\mathrm{c}}$ & $1.8 \pm 0.03^{\mathrm{c}}$ \\
GMP & $0.709 \pm 0.005$ & $0.783 \pm 0.007$ & $0.606 \pm 0.003$ \\
GDP & $0.753 \pm 0.004$ & $0.577 \pm 0.002$ & $0.444 \pm 0.003$ \\
GTP & $0.789 \pm 0.005$ & $0.514 \pm 0.003$ & $0.410 \pm 0.004$ \\
\hline
\end{tabular}

a Reported in Ref. [16].

b Reported in Ref. [17].

c Reported in Ref. [18].

NV, USA) integrated with a UV-vis microplate spectrophotometer (SpectraMax Plus 384, Molecular Devices, Sunnyvale, CA). Solutions of all compounds were prepared in water at concentrations of $0.5-5 \mathrm{mg} / \mathrm{mL}$ depending on the compound solubility. Briefly, varied amounts of compound solution and water were added to a set of the same polymers/buffer or PEG and $\mathrm{Na}_{2} \mathrm{SO}_{4}$ mixtures. The systems were vortexed and centrifuged for $30-60 \mathrm{~min}$ at $23^{\circ} \mathrm{C}$ to accelerate phase settling. The top phase in each system was removed, the interface discarded, and aliquots from the top and bottom phases were withdrawn in duplicate for analysis.

For the analysis of the compounds partitioning, aliquots from both phases were diluted with water, vortexed and centrifuged, aliquots were transferred into microplate wells, and the UV-vis plate reader was used to measure optical absorbance at of maximum absorption wavelengths.

The partition coefficient $K$-value defined as the ratio of the solute concentration in the top PEG-rich phase to the solute concentration in the bottom dextran-rich or salt-rich phase for each solute was determined as the slope of the concentration (absorbance) in the top phase plotted as a function of the concentration in the bottom phase averaged over the results obtained from two to four partition experiments $[11,14,15]$. Deviation from the average $K$-value was consistently below $3 \%$ and in most cases lower than $1 \%$.

\section{Results and discussion}

The partition coefficients of AMP, ADP, ATP, GMP, GDP, and GTP in three ATPSs with previously characterized differences between the hydrophobic and electrostatic properties of the phases [14-16] are listed in Table 1. Some of the partition coefficients for adenine, adenosine, guanosine, AMP, ADP, and ATP in the same ATPSs were reported previously $[17,18]$.

Commonly, the differences between the electrostatic and hydrophobic properties of the coexisting phases of ATPS are estimated by analysis of partitioning of a homologous series of dinitrophenylated (DNP-) amino acids Na salts with aliphatic alkyl side-chains of the increasing length $[5,10,11,14-18]$. The typical data in a given ATPS may be described as [3,8-13]:

$\log K_{\text {DNP-AA }}^{i}=C^{i}+E^{i} \times \mathrm{N}_{\mathrm{C}}$

where $K_{D N P-A A}^{i}$ is the partition coefficient of a DNP-amino acids Nasalt in $i^{\text {th }}$ ATPS; $N_{c}$ is the equivalent number of $\mathrm{CH}_{2}$ groups in the side-chain [13]. Parameter $E$ represents an average contribution of 
a $\mathrm{CH}_{2}$ group into $\log \mathrm{K}$ and characterizes the difference between the hydrophobic properties of the phases $[5,10,11,14-18]$. Parameter C represents the contribution of the polar DNP-NH-CH-COONa moiety. The advantages and drawbacks of using this moiety as a probe for electrostatic properties of the phases were considered in detail in [5]. The obvious drawbacks of using the DNP-NH-CH-COONa moiety as a probe for electrostatic interactions are the volume of the moiety and the presence of substituted aromatic group. It would be preferable to replace this moiety with a moiety capable to participate solely in electrostatic interactions.

We used here the similar approach to analysis of partitioning of mononucleotides with the difference that the number of charged phosphate groups is varied. The data obtained in dextran-PEG ATPS are illustrated in Fig. 1a where logarithms of partition coefficients for the two series of mononucleotides are plotted against the number of phosphate groups. An increase in the number of phosphate groups results in the increase of the nucleotide partition coefficient for both series in dextran-PEG ATPS. The data plotted in Fig. 1a may be described as:

$\log K_{A}=A_{A}+B_{A} \times N_{P}$ and $\log K_{G}=A_{G}+B_{G} \times N_{P}$

where $K_{A}$ and $K_{G}$ are the partition coefficients of a given adenosine phosphate and guanine phosphate respectively; $N_{P}$ is the number of phosphate groups; $A_{A}, A_{G}, B_{A}$, and $B_{G}$ are coefficients with values dependent on the particular mononucleotides examined.

It can be seen in Fig. 1a, however, that the partition behavior of adenosine mononucleotides differs from that of guanine mononucleotides. The parameters $\mathrm{B}_{\mathrm{A}}$ and $\mathrm{B}_{\mathrm{G}}$ representing the average contribution of a phosphate group into $\log K$ of the corresponding nucleotides are $0.0316 \pm 0.0004$ and $0.023 \pm 0.002$ respectively. The observed dependence of the average contributions of a phosphate group on the nature of nucleobase makes it questionable whether contribution of a phosphate group may be used for evaluation of the difference between the electrostatic properties of the phases in ATPS.

The data obtained for the same two series of mononucleotides in PEG- $\mathrm{Na}_{2} \mathrm{SO}_{4}$ ATPS are illustrated graphically in Fig. $1 \mathrm{~b}$. The partition behavior of adenosine mononucleotides as a function of the number of phosphate groups may be described by Eq. (3), while the same dependence for guanine mononucleotides is clearly nonlinear and may be described as:

$\log K_{G}=a_{G}+b_{G} \times \mathrm{e}^{-N p}$

where $a_{G}$ and $b_{G}$ are constants; all the other parameters are as defined above.

Similar dependences in PEG- $\mathrm{Na}_{2} \mathrm{SO}_{4}-0.215 \mathrm{M} \mathrm{NaCl}$ ATPS illustrated in Fig. 1c appear to be nonlinear for both adenosine and guanine mononucleotides series. An increase in the number of phosphate groups results in the decrease of the nucleotide partition coefficient for both series in PEG-Na $\mathrm{SO}_{4}$ ATPS with and without $\mathrm{NaCl}$ additive.

If we assume that the partition behavior of adenosine mononucleotides as a function of the number of phosphate groups may be described by Eq. (3) under all conditions used here and plot the slope of the linear function (coefficient $B_{A}$ ) in all three ATPS versus the parameter $C^{i}$ (Eq. (2)), Fig. 2, used as the estimate of the difference between the electrostatic properties of the phases [5] we observe nonlinear relationship. This nonlinearity is not as important as the change of the sign of the difference between the electrostatic properties of the two phases between dextran-PEG and PEG- $\mathrm{Na}_{2} \mathrm{SO}_{4}$ ATPS observed with adenosine mononucleotides and not detected with DNP-amino acids Na-salts. The previously reported [14-20] studies of partition behavior of small organic compounds and proteins in PEG- $\mathrm{Na}_{2} \mathrm{SO}_{4}$ ATPS with and without $\mathrm{NaCl}$ additive showed that using the difference between the electrostatic properties of the coexisting phases characterized with
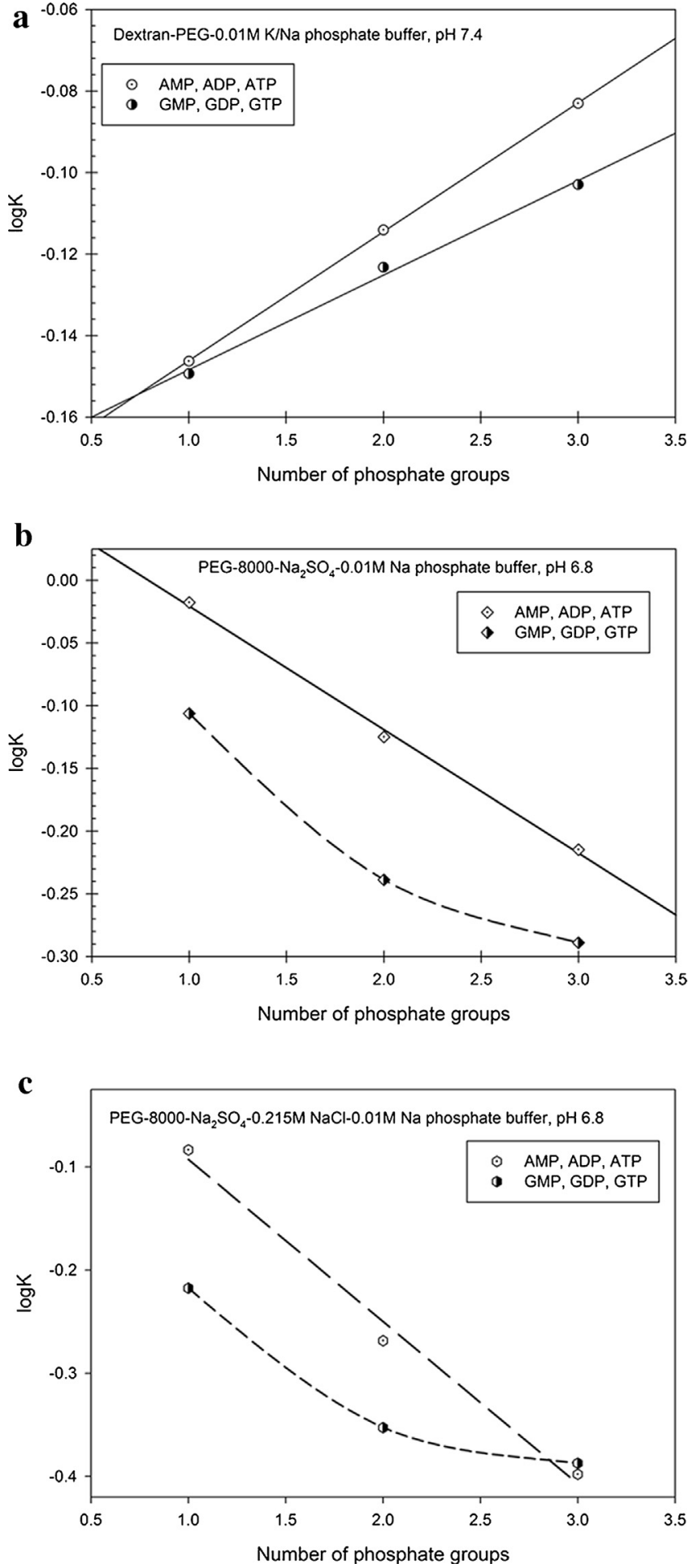

Fig. 1. (a) Logarithm of the partition coefficient value, $\log \mathrm{K}$, for adenosine and guanine mononucleotides with different number of phosphate groups in aqueous dextran-PEG two-phase system as a function of number of phosphate groups: (b) logarithm of the partition coefficient value, $\log \mathrm{K}$, for adenosine and guanine mononucleotides with different number of phosphate groups in aqueous PEG-Na $\mathrm{SO}_{4}$ two-phase system as a function of number of phosphate groups; (c) logarithm of the partition coefficient value, $\log \mathrm{K}$, for adenosine and guanine mononucleotides with different number of phosphate groups in aqueous PEG$\mathrm{Na}_{2} \mathrm{SO}_{4}-0.215 \mathrm{M} \mathrm{NaCl}$ two-phase system as a function of number of phosphate groups. 


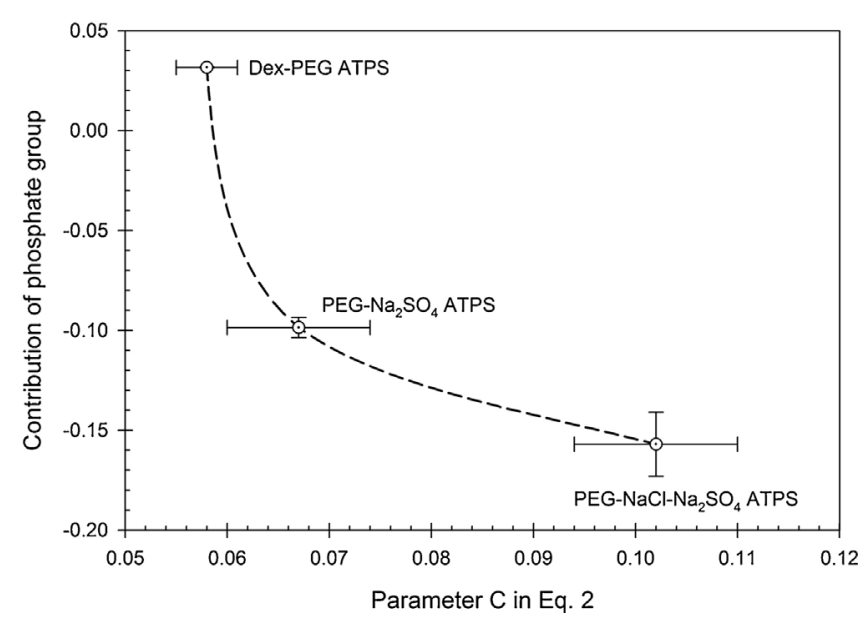

Fig. 2. An average contribution of phosphate group into logarithm of partition coefficient of adenosine mononucleotides versus parameter C in Eq. (2) characterizing the difference between electrostatic properties of two phases in ATPS indicated.

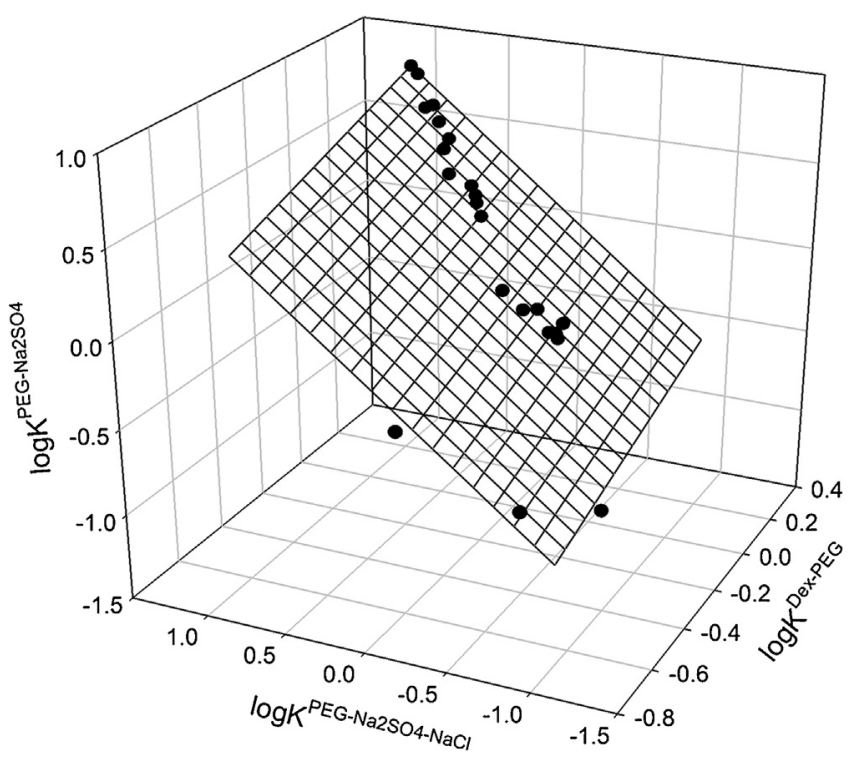

Fig. 3. Logarithms of partition coefficients for organic compounds and proteins in PEG-8000- $\mathrm{Na}_{2} \mathrm{SO}_{4}-0.5 \mathrm{M}$ sorbitol-0.01 M sodium phosphate buffer (NaPB), $\mathrm{pH}$ 6.8 ATPS versus those for the same compounds and proteins in PEG$8000-\mathrm{Na}_{2} \mathrm{SO}_{4}-0.01 \mathrm{M}$ sodium phosphate buffer (NaPB), pH 6.8 ATPS and in PEG-8000- $\mathrm{Na}_{2} \mathrm{SO}_{4}-0.5 \mathrm{M}$ sucrose-0.01 M sodium phosphate buffer (NaPB), pH 6.8 ATPS.

parameter $\mathrm{C}^{\mathrm{i}}$ (Eq. (2)) allowed to estimate the solute-solvent interactions. Hence it seems possible to conclude that the contribution of a phosphate group into partition coefficient of mononucleotide does not provide the reliable estimate of the difference between the electrostatic properties of the phases in PEG-salt ATPS.

All the partition coefficients for small organic compounds and proteins in the three ATPS under consideration reported previously $[3,10-12]$ together with those obtained in this study are presented in Table 2. Analysis of these data shows that there is a linear relationship illustrated in Fig. 3 corresponding to Eq. (1) and described as:

$\log \mathrm{K}_{\mathrm{i}}{ }^{\mathrm{PEG}-\mathrm{Na}_{2} \mathrm{SO}_{4}}=0.05_{ \pm 0.02}+0.5_{ \pm 0.12} \log \mathrm{K}_{\mathrm{i}}$ Dex-PEG

$$
+0.71_{ \pm 0.05} \log \mathrm{K}_{\mathrm{i}}^{\mathrm{PEG}-\mathrm{Na}_{2} \mathrm{SO}_{4}-0.215 \mathrm{M}-\mathrm{NaCl}}
$$

$\mathrm{N}=22 ; \quad \mathrm{r}^{2}=0.9775 ; \quad \mathrm{SD}=0.079 ; \quad \mathrm{F}=412.3 \quad$ where

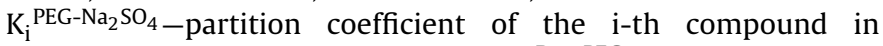

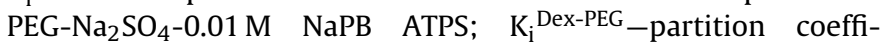

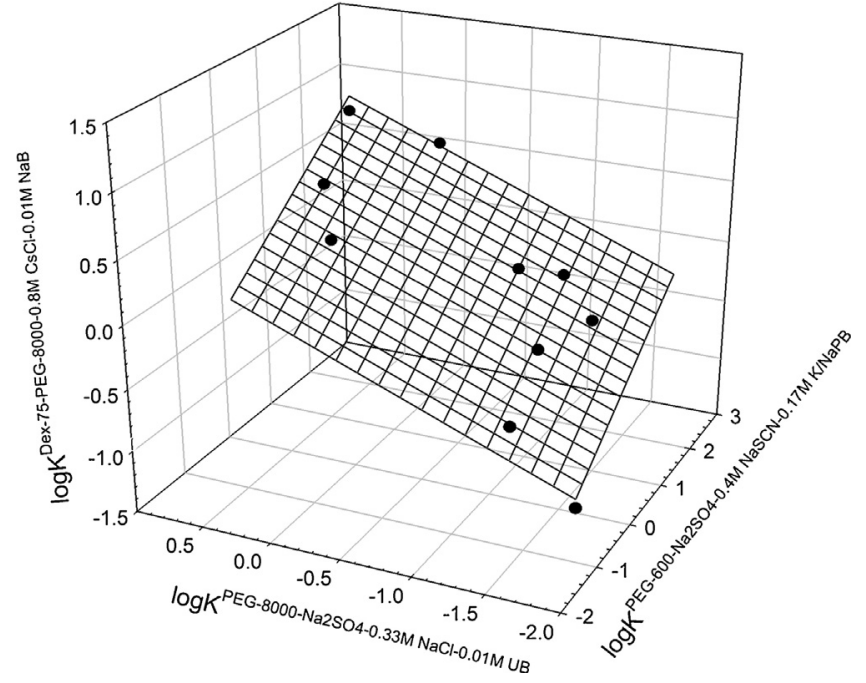

Fig. 4. Logarithms of partition coefficients for organic compounds and proteins in dextran-PEG-8000-0.8 M CsCl-0.01 M sodium phosphate buffer, $\mathrm{pH}$ 7.4 ATPS versus those for the same compounds and proteins in PEG-600- $\mathrm{Na}_{2} \mathrm{SO}_{4}-0.4 \mathrm{M} \mathrm{NaSCN}$ $0.17 \mathrm{M}$ sodium phosphate buffer, pH 7.4 ATPS and in PEG-8000- $\mathrm{Na}_{2} \mathrm{SO}_{4}-0.33 \mathrm{M}$ NaCl-0.01 M universal buffer, pH 7.4 ATPS.

cient of the i-th compound in dextran-PEG-0.01 M K/NaPB

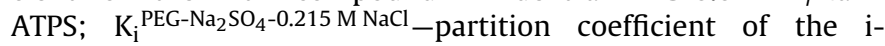
th compound in PEG-Na $\mathrm{SO}_{4}-0.215 \mathrm{M} \quad \mathrm{NaCl}-0.01 \mathrm{M} \quad \mathrm{NaPB}$ ATPS; $\mathrm{N}$-number of compounds (including proteins); $\mathrm{r}^{2}$-correlation coefficient; SD-standard deviation; $\mathrm{F}-$ ratio of variance $(\mathrm{K} / \mathrm{NaPB}-$ sodium/potassium phosphate buffer, $\mathrm{pH} 7.4$; NaPB-sodium phosphate buffer, $\mathrm{pH}$ 6.8).

It should be noted that the above relationship holds for partition coefficients of proteins in PEG- $\mathrm{Na}_{2} \mathrm{SO}_{4}-0.01 \mathrm{M} \mathrm{NaPB}$ and PEG-Na $\mathrm{SO}_{4}-0.215 \mathrm{M} \mathrm{NaCl}-0.01 \mathrm{M}$ NaPB ATPS at pH 6.8 and in dextran-PEG-0.01 M K/NaPB at pH 7.4. This fact seems to imply that the $\mathrm{pH}$ differences as well as the differences in the buffer composition do not affect the nature and spatial arrangement of the solvent exposed groups in the proteins examined.

Previously the similar relationship was reported for partition coefficients of organic compounds and proteins in Dex-PEG ATPS with different ionic composition [11], and in PEG- $\mathrm{Na}_{2} \mathrm{SO}_{4}$ ATPS formed by PEG-8000 and PEG-600 with different salt additives [20]. Analysis of the data reported previously [16,20] shows also that the similar relationship for proteins may be found between polymer-polymer and polymer-salt ATPS. For example the relationship illustrated graphically in Fig. 4 may be described as:

$\log \mathrm{K}_{\mathrm{i}}$ Dex-PEG-0.8 M CsCl-0.01 M NaPB $=0.12_{ \pm 0.10}+0.30$

$$
\begin{aligned}
& \pm 0.07 \log \mathrm{K}_{\mathrm{i}}{ }^{\mathrm{PEG}-600-\mathrm{Na}_{2} \mathrm{SO}_{4}-0.4-\mathrm{NaSCN}-0.17 \mathrm{M} \mathrm{K} / \mathrm{NaPB}} \\
& +0.46_{ \pm 0.08} \log \mathrm{K}_{\mathrm{i}}{ }^{\mathrm{PEG}-8000-\mathrm{Na}_{2} \mathrm{SO}_{4}-0.33 \mathrm{M} \mathrm{NaCl}-0.01 \mathrm{M} \text { UB }}
\end{aligned}
$$

$\mathrm{N}=10 ; \mathrm{r}^{2}=0.9416 ; \mathrm{SD}=0.18 ; \mathrm{F}=56.4$

where $\mathrm{K}_{\mathrm{i}}$ Dex-PEG-0.8 M CsCl-0.01 M NaPB -partition coefficient of the i-th compound in dextran-PEG-0.8 M CsCl-0.01 M NaPB ATPS;

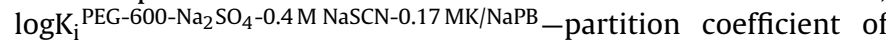
the $i$-th compound in PEG-600-0.4 M NaSCN-0.17 M K/NaPB ATPS;

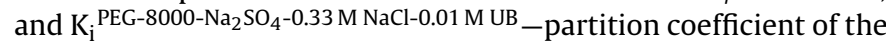
i-th compound in PEG-8000- $\mathrm{Na}_{2} \mathrm{SO}_{4}-0.33 \mathrm{M} \mathrm{NaCl}-0.01 \mathrm{M}$ UB ATPS; all the other parameters are as defined above (NaPB-sodium phosphate buffer, pH 7.4; UB-universal buffer, $\mathrm{pH}$ 7.4). 
Table 2

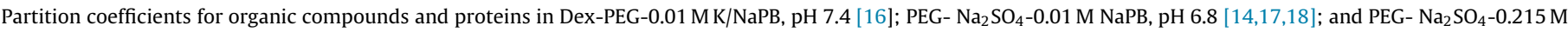
NaCl-0.01 M NaPB, pH 6.8 ATPS [15,17] (NaPB-sodium phosphate buffer; K/NaPB-sodium/potassium phosphate buffer).

\begin{tabular}{|c|c|c|c|}
\hline Compound & $\begin{array}{l}\text { Dex-PEG } \\
0.01 \mathrm{M} \mathrm{K/NaPB}\end{array}$ & $\begin{array}{l}\mathrm{PEG}-\mathrm{Na}_{2} \mathrm{SO}_{4} \\
0.01 \mathrm{M} \mathrm{NaPB}\end{array}$ & $\begin{array}{l}\mathrm{PEG}-\mathrm{Na}_{2} \mathrm{SO}_{4} \\
0.215 \mathrm{M} \mathrm{NaCl}\end{array}$ \\
\hline Adenine & $1.220 \pm 0.006$ & $3.4 \pm 0.12$ & $3.7 \pm 0.16$ \\
\hline Adenosine & $1.128 \pm 0.004$ & $2.63 \pm 0.02$ & $3.12 \pm 0.04$ \\
\hline AMP & $0.714 \pm 0.001$ & $1.02 \pm 0.05$ & $0.83 \pm 0.04$ \\
\hline ADP & $0.769 \pm 0.002$ & $0.77 \pm 0.02$ & $0.54 \pm 0.03$ \\
\hline ATP & $0.826 \pm 0.002$ & $0.61 \pm 0.01$ & $0.40 \pm 0.02$ \\
\hline Benzyl alcohol & $1.409 \pm 0.009$ & $3.500 \pm 0.007$ & $4.067 \pm 0.008$ \\
\hline Caffeine & $1.154 \pm 0.009$ & $1.85 \pm 0.039$ & $2.11 \pm 0.036$ \\
\hline Coumarin & $1.490 \pm 0.009$ & $4.86 \pm 0.014$ & $4.86 \pm 0.014$ \\
\hline Glucopyranoside $^{a}$ & $1.232 \pm 0.003$ & $2.18 \pm 0.023$ & $2.47 \pm 0.033$ \\
\hline Guanosine & $1.068 \pm 0.007$ & $1.673 \pm 0.008$ & $1.8 \pm 0.03$ \\
\hline GMP & $0.709 \pm 0.005$ & $0.783 \pm 0.007$ & $0.606 \pm 0.003$ \\
\hline GDP & $0.753 \pm 0.004$ & $0.577 \pm 0.002$ & $0.444 \pm 0.003$ \\
\hline GTP & $0.789 \pm 0.005$ & $0.514 \pm 0.003$ & $0.410 \pm 0.004$ \\
\hline Methyl anthranilate & $1.77 \pm 0.01$ & $7.28 \pm 0.035$ & $9.59 \pm 0.027$ \\
\hline Phenol & $1.70 \pm 0.02$ & $4.60 \pm 0.084$ & $6.5 \pm 0.17$ \\
\hline 2-Phenylethanol & $1.469 \pm 0.005$ & $4.16 \pm 0.020$ & $4.98 \pm 0.012$ \\
\hline Vanillin & $1.709 \pm 0.009$ & $6.78 \pm 0.027$ & $8.28 \pm 0.020$ \\
\hline$\alpha$-Chymotrypsin & $0.42 \pm 0.01$ & $0.117 \pm 0.001$ & $0.110 \pm 0.001$ \\
\hline$\alpha$-Chymotrypsinogen A & $1.00 \pm 0.01$ & $0.429 \pm 0.003$ & $0.543 \pm 0.003$ \\
\hline Concanavalin A & $0.236 \pm 0.003$ & $0.192 \pm 0.001$ & $0.183 \pm 0.001$ \\
\hline Lysozyme & $0.23 \pm 0.003$ & $0.406 \pm 0.003$ & $0.983 \pm 0.003$ \\
\hline Papain & $1.05 \pm 0.01$ & $2.22 \pm 0.011$ & $1.92 \pm 0.007$ \\
\hline
\end{tabular}

a $p$-nitrophenyl- $\alpha$-D-glucopyranoside.

The above relationships seem to indicate that Eq. (1) is rather universal. These correlations suggest that the properties and mechanism of phase separation in both types of polymer-polymer and polymer-salt ATPS are of the same nature.

We do not know yet the boundaries of its applicability to physicochemical and biological properties. The work in this regard is currently in progress in our laboratories.

\section{Acknowledgments}

Nuno da Silva acknowledges the financial support by Fundação para a Ciência e a Tecnologia (FCT) of the Portuguese's Ministry for Science, Technology and Higher Education, in the framework of the Operational Program COMPETE (PTDC/EQU-FTT/120332/2010).

Pedro P. Madeira acknowledges the financial support in part provided by (i) FCT/MEC and FEDER through COMPETE 2020 (Project UID/EQU/50020/2013-POCI-01-0145-FEDER-006984) and (ii) QREN, FCT, ON2 and FEDER, through COMPETE (Project NORTE07-0124-FEDER-0000011).

\section{References}

[1] P.A. Albertsson, Partition of Cell Particles and Macromolecules, 3rd ed., Wiley, New York, 1986.

[2] Partitioning in Aqueous Two-phase Systems: Theory, Methods, Use, and Applications to Biotechnology, in: H. Walter, D.E. Brooks, D. Fisher (Eds.), Academic Press, Orlando, FL, 1985.

[3] Aqueous Two-Phase Systems, in: H. Walter, G. Johansson (Eds.), Academic Press, New York, 1994.

[4] R. Hatti-Kaul, Aqueous Two-Phase Systems. Methods and Protocols, in: R Hatti-Kaul (Ed.), Humana Press, Totowa, 2000.

[5] B.Y. Zaslavsky, Aqueous Two-phase Partitioning: Physical Chemistry and Bioanalytical Applications, CRC Press, 1994.

[6] R.R. Soares, A.M. Azevedo, J.M. Van Alstine, M.R. Aires-Barros, Partitioning in aqueous two-phase systems: analysis of strengths, weaknesses, opportunities and threats, Biotechnol. J. 10 (2015) 1158-1169.

[7] B.Y. Zaslavsky, V.N. Uversky, A. Chait, Analytical applications of partitioning in aqueous two-phase systems: exploring protein structural changes and protein-partner interactions in vitro and in vivo by solvent interaction analysis method, Biochim. Biophys. Acta 1864 (2016) 622-644.
[8] M.G. Freire, A.F.M. Cláudio, J.M.M. Araújo, J.A.P. Coutinho, I.M. Marrucho, J.N.C. Lopes, L.P.N. Rebelo, Aqueous biphasic systems: a boost brought about by using ionic liquids, Chem. Soc. Rev. 41 (2012) 4966-4995.

[9] L.A. Ferreira, A. Chervenak, S. Placko, A. Kestranek, P.P. Madeira, B.Y. Zaslavsky, Responses of polar organic compounds to different ionic environment in aqueous media are interrelated, Phys. Chem. Chem. Phys. 16 (2014) 23341-23342.

[10] L.A. Ferreira, A. Chervenak, S. Placko, A. Kestranek, P.P. Madeira, B.Y. Zaslavsky, Effect of ionic composition on partitioning of organic compounds in octanol-buffer systems, RSC Adv. 5 (2015) 20574-20582.

[11] L.A. Ferreira, P.P. Madeira, A.V. Uversky, V.N. Uversky, B.Z. Zaslavsky, Responses of proteins to different ionic environment are linearly interrelated, J. Chromatogr. A 1387 (2015) 32-41.

[12] P.L. Nostro, B.W. Ninham, S. Milani, L. Fratoni, P. Baglioni, Specific anion effects on the optical rotation of glucose and serine, Biopolymers 81 (2006) 136.

[13] S. Rossi, L.P. Nostro, M. Lagi, B.W. Ninham, P. Baglioni, Specific anion effects on the optical rotation of alpha-amino acids, J. Phys. Chem. B 111 (2007) 10510

[14] N. da Silva, L.A. Ferreira, P.P. Madeira, J.A. Teixeira, V.N. Uversky, B.Y. Zaslavsky, Analysis of partitioning of organic compounds and proteins in aqueous polyethylene glycol-sodium sulfate aqueous two-phase systems in terms of solute-solvent interactions, J. Chromatogr. A 1415 (2015) 1-10.

[15] N. da Silva, L.A. Ferreira, P.P. Madeira, J.A. Teixeira, V.N. Uversky, B.Y. Zaslavsky, Effect of $\mathrm{NaCl}$ additive on solute-solvent interactions in aqueous polyethylene glycol-sodium sulfate two-phase systems, J. Chromatogr. A 1425 (2015) 51-61.

[16] L.A. Ferreira, X. Fan, P.P. Madeira, L. Kurgan, V.N. Uversky, B.Y. Zaslavsky, Analyzing the effects of protecting osmolytes on solute-water interactions by solvatochromic comparison method: II. Globular proteins, RSC Adv. 5 (2015) 59780-59791.

[17] L.A. Ferreira, J.A. Teixeira, L.M. Mikheeva, A. Chait, B.Y. Zaslavsky, Effect of salt additives on partition of nonionic solutes in aqueous PEG-sodium sulfate two-phase system, J. Chromatogr. A 1218 (2011) 5031-5039.

[18] N. da Silva, L.A. Ferreira, L.M. Mikheeva, J. Teixeira, B.Y. Zaslavsky, Origin of salt additive effect on solute partitioning in aqueous PEG- sodium sulfate two-phase system, J. Chromatogr. A 1337 (2014) 3-8.

[19] L.A. Ferreira, P. Parpot, J.A. Teixeira, L.M. Mikheeva, B.Y. Zaslavsky, Effect of $\mathrm{NaCl}$ additives on properties of aqueous PEG- sodium sulfate two-phase system, J. Chromatogr. A 1220 (2012) 14-20.

[20] L.A. Ferreira, P. Madeira, L.M. Mikheeva, V. Uversky, B. Zaslavsky, Effect of salt additives on protein partition in polyethylene glycol-sodium sulfate aqueous two-phase systems, Biochim. Biophys. Acta 1834 (2013) 2859-2866. 